\title{
Predictors of mortality among patients undergoing colectomy for ischemic colitis: A population-based, United States study
}

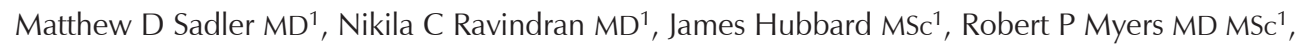 \\ Subrata Ghosh MD ${ }^{1}$, Paul L Beck MD PhD ${ }^{1}$, Elijah Dixon MD MSc ${ }^{3}$, Chad Ball MD ${ }^{3}$, Chris Prusinkiewicz MD ${ }^{4}$, \\ Steven J Heitman MD MSc${ }^{1}$, Gilaad G Kaplan MD MPH ${ }^{1,2}$
}

\begin{abstract}
MD Sadler, NC Ravindran, J Hubbard, et al. Predictors of mortality among patients undergoing colectomy for ischemic colitis: A population-based, United States study. Can J Gastroenterol Hepatol 2014;28(11):600-604.
\end{abstract}

BACKGROUND: Ischemic colitis is a potentially life-threatening condition that can require colectomy for management.

OBJECTIVE: To assess independent predictors of mortality following colectomy for ischemic colitis using a nationally representative sample of hospitals in the United States.

METHODS: The Nationwide Inpatient Sample was used to identify all patients with a primary diagnosis of acute vascular insufficiency of the colon (International Classification of Diseases, Ninth Revision codes 557.0 and 557.9) who underwent a colectomy between 1993 and 2008. Incidence and mortality are described; multivariate logistic regression analysis was performed to determine predictors of mortality. RESULTS: The incidence of colectomy for ischemic colitis was 1.43 cases ( $95 \%$ CI 1.40 cases to 1.47 cases) per 100,000 . The incidence of colectomy for ischemic colitis increased by $3.1 \%$ per year (95\% CI 2.3\% to 3.9\%) from 1993 to 2003 , and stabilized thereafter. The postoperative mortality rate was $21.0 \%$ (95\% CI $20.2 \%$ to $21.8 \%)$. After 1997 , the mortality rate significantly decreased at an estimated annual rate of $4.5 \%$ (95\% CI $-6.3 \%$ to $-2.7 \%)$. Mortality was associated with older age, 65 to 84 years (OR 5.45 [95\% CI 2.91 to 10.22]) versus 18 to 34 years; health insurance, Medicaid (OR 1.69 [95\% CI 1.29 to 2.21]) and Medicare (OR 1.33 [95\% CI 1.12 to 1.58 ]) versus private health insurance; and comorbidities such as liver disease (OR 3.54 [95\% CI 2.79 to 4.50]). Patients who underwent colonoscopy or sigmoidoscopy (OR 0.78 [95\% CI 0.65 to 0.93]) had lower mortality.

CONCLUSIONS: Colectomy for ischemic colitis was associated with considerable mortality. The explanation for the stable incidence and decreasing mortality rates observed in the latter part of the present study should be explored in future studies.

Key Words: Colectomy; Incidence; Ischemic colitis; Mortality; Temporal trends
Les prédicteurs de mortalité chez les patients qui subissent une colectomie secondaire à une colite ischémique : une étude en population menée aux États-Unis

HISTORIQUE : La colite ischémique est une maladie au potentiel mortel dont la prise en charge peut exiger une colectomie.

OBJECTIF : Évaluer les prédicteurs indépendants de mortalité après une colectomie secondaire à une colite ischémique au moyen d'un échantillon national représentatif d'hôpitaux des États-Unis.

MÉTHODOLOGIE : Pour repérer tous les patients ayant un diagnostic primaire d'insuffisance vasculaire aiguë du côlon (Classification internationale des maladies, Neuvième révision, codes 557.0 et 557.9), les chercheurs ont utilisé l'échantillon national de patients hospitalisé qui ont subi une colectomie entre 1993 et 2008. Ils en décrivent l'incidence et la mortalité et ont utilisé l'analyse par régression logistique pour déterminer les prédicteurs de mortalité.

RÉSULTATS : L'incidence de colectomie secondaire à la colite ischémique s'élevait à 1,43 cas (95\% IC 1,40 à 1,47 cas) sur 100000 habitants. L'incidence de colectomie secondaire à la colite ischémique a augmenté de 3,1 \% par année (95 \% IC 2,3 \% à 3,9 \%) entre 1993 et 2003 et s'est stabilisée par la suite. Le taux de mortalité postopératoire était de 21,0\% (95\% IC 20,2 \% à 21,8\%). Après 1997, le taux de mortalité a considérablement diminué, à un taux annuel estimatif de 4,5\% (95\% IC $-6,3 \%$ à $-2,7 \%$ ). La mortalité s'associait à un âge plus avancé, de 65 à 84 ans (RC 5,45 [95 \% IC 2,91 à 10,22]) par rapport à 18 à 34 ans; à l'assurance-maladie comme Medicaid (RC 1,69 [95 \% IC 1,29 à 2,21]) et Medicare ( $\mathrm{RC} 1,33$ [95 \% IC 1,12 à 1,58]) plutôt qu'à l'assurancemaladie privée, et à des comorbidités comme les hépatopathies (RC 3,54 [95 \% IC 2,79 à 4,50]). Les patients qui avaient subi une coloscopie ou une sigmoïdoscopie (RC 0,78 [95 \% IC 0,65 à 0,93]) présentaient une mortalité moins élevée.

CONCLUSIONS : La colectomie secondaire à la colite ischémique s'associait à une mortalité considérable. Dans le cadre de prochaines études, il faudrait chercher à expliquer la stabilisation de l'incidence et la diminution du taux de mortalité observées dans la dernière partie de la présente étude.

The prognosis for ischemic colitis is variable, with many patients experiencing mild events that do not require hospitalization. However, others require admission to hospital for physiological support and risk stratification. Patients with severe presentations may require a segmental or total colectomy to manage complications of ischemic colitis. Mortality among patients with ischemic colitis who require colectomy is high. However, predictors for risk stratification for mortality are lacking in the literature.

We assessed in-hospital mortality following colectomy for ischemic colitis and determined independent predictors of mortality sigmoidoscopies showed evidence of ischemic colitis (5).

\footnotetext{
${ }^{1}$ Departments of Medicine; ${ }^{2}$ Community Health Sciences; ${ }^{3}$ Surgery; ${ }^{4}$ Anesthesia, University of Calgary, Calgary, Alberta

Correspondence: Dr Gilaad Kaplan, Teaching Research and Wellness Centre, 3280 Hospital Drive Northwest, 6D56, Calgary, Alberta T2N 4N1 .

Telephone 403-592-5015, fax 403-592-5090, e-mail ggkaplan@ucalgary.ca

Received for publication October 26, 2014. Accepted November 7, 2014
} 
following colonic resection using a nationally representative sample of hospitals in the US.

\section{METHODS}

\section{Data source}

Data were extracted from the Healthcare Cost and Utilization Project Nationwide Inpatient Sample (NIS) database for the years 1993 to 2008. The NIS database contains hospital discharge abstracts from approximately $20 \%$ of nonfederal acute care hospitals in the US. Stratified random sampling was performed to ensure that the database was representative of the US population, and accounts for approximately $90 \%$ of all hospitalizations, including community and academic centres, but not long-term care facilities. The NIS contains information on demographic characteristics, up to 15 diagnostic and procedure codes based on the International Classification of Diseases, Ninth Revision, Clinical Modification (ICD-9-CM), outcomes and hospital characteristics. Because each record is for a single hospitalization - not a person - multiple records are possible for an individual with recurrent hospitalizations. NIS data compare favourably with the National Hospital Discharge Survey, supporting the validity of this database (6). Quality control and validation of the NIS are performed by the Agency for Healthcare Research and Quality in Rockville, Maryland (USA) (7). The NIS database has been used extensively to study nationwide outcomes for incidence, health service utilization and inhospital mortality (8-11).

\section{Study sample}

ICD-9-CM diagnosis codes were used to identify 10,111 discharges of patients with a primary diagnosis of acute vascular insufficiency of the intestine (codes 557.0 and 557.9) who were admitted emergently from 1993 to 2008, and underwent a segmental or total colectomy (codes 45.7 or 45.8 ). Individuals with a co-existing ICD-9-CM procedural code for a small bowel resection (codes 45.50, 45.51, 45.6 and 45.72) were excluded to remove patients with ischemic small bowel. Patients with a secondary diagnosis of acute vascular insufficiency were excluded to avoid patients who experienced vascular insufficiency as a complication of their primary admission. Patients who were admitted electively were also excluded. The cohort was limited to adults 18 to 84 years of age.

\section{Study variables}

The primary outcome of interest was in-hospital mortality following colectomy for ischemic colitis. Demographic variables evaluated included: age at diagnosis, categorized as 18 to 34,35 to 49,50 to 64 and 65 to 84 years; sex; race and ethnicity, classified as Caucasian, African American, Hispanic, Asian or other/unknown; and health care insurance status, categorized as private, Medicare, Medicaid, self-pay or other/unknown. The following Charlson index comorbidities were assessed: myocardial infarction, congestive heart failure, peripheral vascular disease, cerebrovascular disease, dementia, chronic pulmonary disease, rheumatic disease, peptic ulcer disease, mild liver disease, moderate or severe liver disease, diabetes without chronic complications, diabetes with chronic complications, hemiplegia or paraplegia, renal disease, cancer, metastatic solid tumour and AIDS/HIV (12). Hospital characteristics evaluated included hospital location, classified as rural, urban teaching or urban nonteaching, and hospital region, categorized as Midwest, South, West or Northeast.

\section{Statistical analysis}

Calculation of percentages and logistic regression analyses were performed using SAS-callable SUDAAN release 11.0.0 (Research Triangle Institute, USA) to adjust for the complex sampling design of the NIS. Joinpoint Regression Program version 4.0.1 (Statistical Research and Applications Branch, National Cancer Institute, USA) was used to detect inflection points across time, and temporal analyses were performed using SAS version 9.3 (SAS Institute Inc, USA) Figures were created using Stata Statistical Software release 11.2 (StataCorp LP, USA).
Discharge-level weights were used to produce 95\% CIs for point estimates and to reflect nationwide data during the study period. The annual incidence and mortality for patients who underwent colectomy for ischemic colitis in the US population were determined. The annual incidence and mortality rates were calculated by dividing the weighted estimate for all annual admissions/deaths in US hospitals by the annual civilian population size for the US using estimates from census data. For each annual incidence and mortality rate, 95\% CIs were calculated. Temporal changes in the incidence and mortality rates were calculated using generalized linear regression models that assumed a Poisson distribution and adjusted for overdispersion. Additionally, Joinpoint models were used to assess for statistical inflection points in the temporal trends; models with zero, one or two inflection points were tested to determine whether the trend would be best modelled by zero, one or two regression segments.

Multivariable logistic regression using generalized estimating equations to account for clustering of discharges within hospitals was performed to evaluate factors that predicted in-hospital mortality in patients who underwent colectomy for ischemic colitis. Covariates assessed in the model included demographics, Charlson index comorbidities and procedures implemented in the management of acute vascular insufficiency of the colon (eg, colonoscopy). Point estimates were represented as adjusted ORs with 95\% CIs. Two-sided P values were reported with a significance level of 0.05 .

\section{RESULTS}

Between 1993 and 2008, the NIS database sampled 10,111 discharges for ischemic colitis patients who underwent colectomy. The characteristics of ischemic colitis patients requiring colectomy are summarized in Table 1 .

\section{Incidence}

The overall incidence for colectomy for ischemic colitis was 1.43 cases per 100,000 person-years ( $95 \%$ CI 1.40 cases to 1.47 cases). Between 1993 and 2008, the incidence rate for colectomies in patients with ischemic colitis significantly increased $(\mathrm{P}=0.0004)$ (Figure 1). Over the 16-year study period, the estimated annual percent change (APC) in incidence rates was $1.4 \%(95 \% \mathrm{CI} 0.6 \%$ to $2.3 \%$; $\mathrm{P}=0.0004)$. A statistically significant inflection point was observed in 2003. Between 1993 and 2003, the incidence rate increased significantly at an annual rate of $3.1 \%$ (95\% CI $2.3 \%$ to $3.9 \%$ ), whereas the incidence rate between 2003 and 2008 was stable (APC $-2.1 \%$ [95\% CI $-4.7 \%$ to $0.6 \%])$.

\section{Mortality}

Among patients who were emergently admitted to hospital for ischemic colitis and underwent colectomy, 21.0\% (95\% CI 20.2\% to $21.8 \%)$ died in hospital. The overall mortality rate in the US was 0.30 per 100,000 population ( $95 \%$ CI 0.29 to 0.31 ). A statistically significant inflection point for mortality was observed in 1997. Between 1993 and 1997, the mortality rate of colectomy for ischemic colitis increased significantly at an annual mean rate of $10.1 \%$ (95\% CI $4.5 \%$ to $16.0 \%)$. After 1997 , the mortality rate decreased significantly (APC $-4.5 \%$ [95\% CI $-6.3 \%$ to $-2.7 \%]$ ) (Figure 2).

In multivariate logistic regression analysis, several factors were found to predict mortality following colectomy for ischemic colitis (Table 1). Patients 65 to 84 years of age were more likely to die (OR 5.45 [95\% CI 2.91 to 10.22]) compared with the age group 18 to 34 years; and patients with Medicaid insurance (OR 1.69 [95\% CI 1.29 to 2.21]) and Medicare insurance (OR 1.33 [95\% CI 1.12 to 1.58]) were more likely to die compared with those with private insurance. Comorbidities such as liver disease (OR 3.54 [95\% CI 2.79 to 4.50]) were associated with increased risk for mortality, whereas other comorbidities such as diabetes (OR 0.57 [95\% CI 0.42 to 0.77]) were negatively associated with death (Table 1 ). Patients who underwent colonoscopy or sigmoidoscopy had a lower risk for death (OR 0.78 [95\% CI 0.65 to 0.93$]$ ) (Table 1 ). 
TABLE 1

Predictors of in-hospital mortality in patients who underwent colectomy for ischemic colitis between 1993 and 2008

\begin{tabular}{|c|c|c|c|}
\hline Variable & $\begin{array}{l}\%(95 \% \mathrm{Cl}) \\
(\mathrm{n}=10,111)\end{array}$ & $\begin{array}{c}\text { Mortality, \% } \\
(95 \% \mathrm{Cl})(\mathrm{n}=2112)\end{array}$ & $\begin{array}{l}\text { Adjusted OR } \\
(95 \% \mathrm{Cl})\end{array}$ \\
\hline \multicolumn{4}{|l|}{ Age, years } \\
\hline $18-34$ & $2.1(1.8-2.4)$ & $5.2(2.9-9.2)$ & 1.00 \\
\hline $35-49$ & $6.6(6.2-7.1)$ & $10.4(8.3-12.9)$ & $1.84(0.95-3.57)$ \\
\hline $50-64$ & $22.5(21.6-23.3)$ & $15.4(13.9-16.9)$ & $3.17(1.71-5.89)$ \\
\hline $65-84$ & $68.8(67.8-69.7)$ & $24.3(23.3-25.4)$ & $5.45(2.91-10.22)$ \\
\hline \multicolumn{4}{|l|}{ Sex } \\
\hline Male & $38.7(37.7-39.6)$ & $21.6(20.3-22.9)$ & 1.00 \\
\hline Female & $61.3(60.4-62.3)$ & $20.6(19.6-21.6)$ & $0.94(0.85-1.04)$ \\
\hline \multicolumn{4}{|l|}{ Race } \\
\hline Caucasian & $63.7(62.3-65.1)$ & $21.2(20.2-22.2)$ & 1.00 \\
\hline $\begin{array}{l}\text { African } \\
\text { American }\end{array}$ & $6.3(5.8-6.9)$ & $21.6(18.4-25.1)$ & $0.93(0.75-1.16)$ \\
\hline Hispanic & $3.0(2.7-3.4)$ & $20.6(16.4-25.5)$ & $0.94(0.69-1.28)$ \\
\hline Asian & $0.5(0.3-0.6)$ & $15.3(7.6-28.6)$ & $0.66(0.28-1.52)$ \\
\hline Other/unknown & $26.5(25.1-27.9)$ & 20.5 (18.9-22.1) & $1.03(0.91-1.18)$ \\
\hline \multicolumn{4}{|l|}{ Health Insurance } \\
\hline Private & $21.2(20.4-22.1)$ & $12.9(11.5-14.4)$ & 1.00 \\
\hline Medicare & $69.8(68.8-70.7)$ & $23.8(22.8-24.9)$ & $1.33(1.12-1.58)$ \\
\hline Medicaid & $5.0(4.5-5.4)$ & $19.2(16.0-22.8)$ & $1.69(1.29-2.21)$ \\
\hline Self-pay & $2.0(1.8-2.3)$ & $13.9(9.7-19.6)$ & $1.30(0.84-2.03)$ \\
\hline Other/unknown & $2.0(1.7-2.3)$ & $18.3(13.6-24.1)$ & $1.41(0.97-2.06)$ \\
\hline \multicolumn{4}{|l|}{ Hospital location } \\
\hline Rural & $14.4(13.5-15.3)$ & $19.0(16.8-21.3)$ & 1.00 \\
\hline $\begin{array}{l}\text { Urban, } \\
\text { nonteaching }\end{array}$ & $44.2(42.9-45.5)$ & 20.7 (19.5-21.9) & $1.12(0.95-1.33)$ \\
\hline $\begin{array}{l}\text { Urban, } \\
\text { teaching }\end{array}$ & $41.4(40.1-42.7)$ & $22.0(20.7-23.4)$ & $1.24(1.05-1.47)$ \\
\hline \multicolumn{4}{|c|}{ Hospital region, United States } \\
\hline Northeast & $22.1(21.0-23.3)$ & $22.6(20.8-24.6)$ & 1.00 \\
\hline Midwest & $26.0(24.9-27.1)$ & $19.8(18.2-21.4)$ & $0.84(0.71-0.98)$ \\
\hline South & $41.7(40.5-43.0)$ & $22.1(20.8-23.4)$ & $0.97(0.85-1.12)$ \\
\hline West & $10.2(9.3-11.1)$ & $16.0(13.8-18.4)$ & $0.71(0.57-0.88)$ \\
\hline \multicolumn{4}{|c|}{ Myocardial infarction } \\
\hline No & $91.5(90.9-92.0)$ & $20.7(19.9-21.6)$ & 1.00 \\
\hline Yes & $8.5(8.0-9.1)$ & $23.7(20.9-26.6)$ & $1.09(0.91-1.30)$ \\
\hline \multicolumn{4}{|c|}{ Congestive heart failure } \\
\hline No & $77.9(77.1-78.7)$ & $19.2(18.3-20.1)$ & 1.00 \\
\hline Yes & $22.1(21.3-22.9)$ & $27.2(25.4-29.2)$ & $1.33(1.18-1.50)$ \\
\hline \multicolumn{4}{|c|}{ Peripheral vascular disease } \\
\hline No & $91.1(90.5-91.7)$ & $21.2(20.3-22.0)$ & 1.00 \\
\hline Yes & $8.9(8.3-9.5)$ & $19.1(16.7-21.8)$ & $0.81(0.68-0.98)$ \\
\hline \multicolumn{4}{|c|}{ Cerebrovascular disease } \\
\hline No & $95.7(95.3-96.1)$ & $20.6(19.8-21.5)$ & 1.00 \\
\hline Yes & $4.3(3.9-4.7)$ & $28.4(24.2-33.0)$ & $1.46(1.15-1.86)$ \\
\hline \multicolumn{4}{|l|}{ Dementia } \\
\hline No & $98.8(98.6-99.0)$ & $21.0(20.2-21.8)$ & 1.00 \\
\hline Yes & $1.2(1.0-1.4)$ & $19.6(12.9-28.7)$ & $0.85(0.50-1.44)$ \\
\hline \multicolumn{4}{|c|}{ Chronic pulmonary disease } \\
\hline No & $71.8(70.9-72.7)$ & $20.4(19.4-21.4)$ & 1.00 \\
\hline Yes & $28.2(27.3-29.1)$ & $22.5(21.0-24.1)$ & $1.04(0.93-1.16)$ \\
\hline \multicolumn{4}{|l|}{ Rheumatic disease } \\
\hline No & $96.9(96.5-97.2)$ & $20.9(20.1-21.8)$ & 1.00 \\
\hline Yes & $3.1(2.8-3.5)$ & $22.6(18.3-27.6)$ & $1.22(0.92-1.61)$ \\
\hline \multicolumn{4}{|l|}{ Peptic ulcer disease } \\
\hline No & $97.9(97.6-98.1)$ & $20.8(20.0-21.6)$ & 1.00 \\
\hline Yes & $2.1(1.9-2.4)$ & $29.3(23.5-35.7)$ & $1.50(1.10-2.04)$ \\
\hline
\end{tabular}

Continued in next column
TABLE 1 - CONTINUED

Predictors of in-hospital mortality in patients who underwent colectomy for ischemic colitis between 1993 and 2008

\begin{tabular}{|c|c|c|c|}
\hline Variable & $\begin{array}{l}\%(95 \% \mathrm{Cl}) \\
(\mathrm{n}=10,111)\end{array}$ & $\begin{array}{c}\text { Mortality, \% } \\
(95 \% \text { Cl) }(n=2112)\end{array}$ & $\begin{array}{c}\text { Adjusted OR } \\
(95 \% \mathrm{Cl})\end{array}$ \\
\hline \multicolumn{4}{|c|}{ Mild liver disease } \\
\hline No & $96.3(95.9-96.7)$ & $20.1(19.3-20.9)$ & 1.00 \\
\hline Yes & $3.7(3.3-4.1)$ & $44.6(39.6-49.8)$ & $3.54(2.79-4.50)$ \\
\hline \multicolumn{4}{|c|}{ Diabetes without chronic complication } \\
\hline No & $84.7(84.0-85.4)$ & $21.6(20.7-22.5)$ & 1.00 \\
\hline Yes & $15.3(14.6-16.0)$ & $17.5(15.6-19.5)$ & $0.71(0.61-0.83)$ \\
\hline \multicolumn{4}{|c|}{ Diabetes with chronic complication } \\
\hline No & $96.5(96.1-96.9)$ & $21.1(20.3-22.0)$ & 1.00 \\
\hline Yes & $3.5(3.1-3.9)$ & $17.3(13.7-21.6)$ & $0.57(0.42-0.77)$ \\
\hline \multicolumn{4}{|c|}{ Hemiplegia or paraplegia } \\
\hline No & $99.1(98.9-99.3)$ & $21.0(20.2-21.8)$ & 1.00 \\
\hline Yes & $0.9(0.7-1.1)$ & $19.8(12.5-30.1)$ & $0.98(0.53-1.79)$ \\
\hline \multicolumn{4}{|c|}{ Renal disease } \\
\hline No & $87.2(86.5-87.9)$ & $19.1(18.3-20.0)$ & 1.00 \\
\hline Yes & $12.8(12.1-13.5)$ & $33.5(30.9-36.3)$ & $2.23(1.92-2.58)$ \\
\hline \multicolumn{4}{|l|}{ Cancer } \\
\hline No & $96.0(95.6-96.4)$ & $20.6(19.7-21.4)$ & 1.00 \\
\hline Yes & $4.0(3.6-4.4)$ & $31.0(26.8-35.6)$ & $1.72(1.35-2.18)$ \\
\hline \multicolumn{4}{|c|}{ Moderate or severe liver disease } \\
\hline No & 99.5 (99.3-99.6) & $20.8(20.0-21.7)$ & 1.00 \\
\hline Yes & $0.5(0.4-0.7)$ & $47.4(34.7-60.5)$ & $2.17(1.17-4.04)$ \\
\hline \multicolumn{4}{|c|}{ Metastatic solid tumour } \\
\hline No & $98.5(98.3-98.8)$ & $20.8(20.0-21.7)$ & 1.00 \\
\hline Yes & $1.5(1.2-1.7)$ & $30.2(23.3-38.2)$ & $1.41(0.92-2.17)$ \\
\hline \multicolumn{4}{|c|}{ AIDS/HIV } \\
\hline No & $99.86(99.77-99.92)$ & $21.0(20.1-21.8)$ & 1.00 \\
\hline Yes & $0.14(0.08-0.23)$ & $34.2(14.9-60.6)$ & $2.43(0.66-8.92)$ \\
\hline \multicolumn{4}{|c|}{ Colonoscopy or sigmoidoscopy } \\
\hline No & $90.6(90.0-91.2)$ & $21.3(20.4-22.2)$ & 1.00 \\
\hline Yes & $9.4(8.8-10.0)$ & $17.9(15.6-20.5)$ & $0.78(0.65-0.93)$ \\
\hline
\end{tabular}

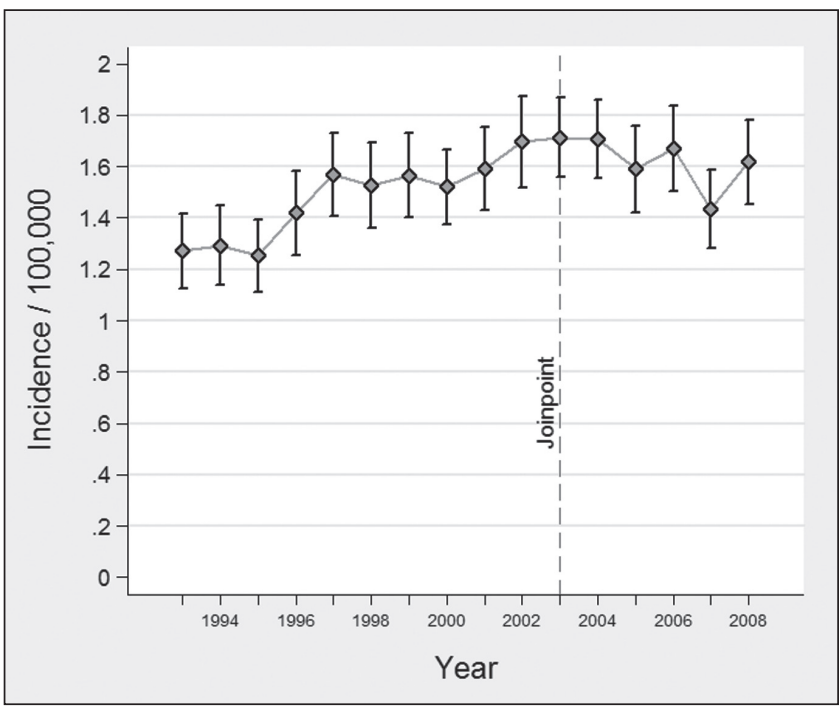

Figure 1) Annual incidence rates of ischemic colitis for patients requiring colectomy in the United States between 1993 and 2008

\section{DISCUSSION}

The present population-based study evaluated the incidence of and mortality from colectomy for ischemic colitis in the US using a nationally representative sample. As the North American population ages, 
we will likely observe an increasing number of admissions to hospital for ischemic colitis. Reassuringly, the annual incidence of colectomy for ischemic colitis has stabilized since 2003. This is important because colectomy for ischemic colitis was associated with significant mortality. Nearly one in five patients who were emergently admitted to hospital with ischemic colitis and required a colectomy subsequently died in hospital.

Our sample specifically assessed hospitalized patients with ischemic colitis who required colectomy. The present study was not designed to analyze patients with ischemic colitis not requiring hospital admission, or who were admitted to hospital but did not require colectomy. Furthermore, patients with ischemic colitis who died in hospital before colectomy were not evaluated. Additionally, acute vascular insufficiency of the colon occurring as an in-hospital complication (eg, postsurgery) was not included in the present study. Nonetheless, the high mortality associated with this condition necessitates prospective studies to evaluate modifiable factors that may prevent the occurrence of ischemic colitis or mitigate mortality among patients with ischemic colitis who require colectomy.

While the incidence of colectomy for ischemic colitis has not decreased, mortality rates have decreased significantly since 1997. These results suggest that clinical detection and management may be improving across time. Cardiovascular risk factor modification strategies (eg, smoking cessation, improved diabetes management, etc) have improved during our study period (13), and may have indirectly reduced the burden of disease. Further advances in surgical management and postoperative management, including intensive care management, may have improved mortality outcomes. Additional studies will be needed to explain potential causes of the decline in mortality rates observed after 1997.

Several important risk factors for mortality and surgery were identified. Our study demonstrated that colonic resection increased the risk for death. Brandt et al (14) also showed that mortality was higher $(37 \%)$ in patients needing surgery compared with those managed medically $(5.6 \%)$. However, surgical resection may simply act as a surrogate for patients with increased disease severity. Also, patients without private insurance were at increased risk for mortality and colonic resection. Such patients may have been disenfranchised with increased barriers to early access to health care, contributing to worse disease states and outcome (15). Furthermore, these patients may have had lower socioeconomic status and may have been more likely to have cardiovascular risk factors (eg, smoking).

Other predictors of mortality identified in our study included advancing age and specific comorbidities including liver disease, renal disease and congestive heart failure. Other studies have reported that hyperthyroidism, stroke, cancer, hepatitis $\mathrm{C}$ and renal dysfunction increase mortality $(2,13,14,16-19)$. Thus, clinicians should cautiously monitor patients with these comorbidities who are admitted with ischemic colitis. Future studies are necessary to evaluate whether a prediction rule for mortality can be generated from at-risk comorbidities.

Patients who underwent colonoscopy or sigmoidoscopy were less likely to die. Patients who undergo these procedures present with more classic symptoms, such as hematochezia, which warrants earlier diagnostic intervention and medical management. Patients who undergo endoscopic evaluation may also represent those receiving additional expert management by a gastroenterologist or surgeon. Alternatively, gastroenterologists are less likely to endoscopically evaluate ill patients at risk for perforation or unable to tolerate sedation. Consequently, the reduced mortality associated with endoscopic evaluation may have been biased by confounding by indication.

Our results should be interpreted in the context of the limitations associated with the use of administrative databases $(20,21)$. First, our study population was based on the ICD-9 code for vascular insufficiency of the intestine, which does not have the specificity to differentiate ischemic colitis from small bowel infarction. However, all of our patients underwent a partial or total colectomy, and we excluded all patients who underwent a concurrent small bowel resection. Also, a

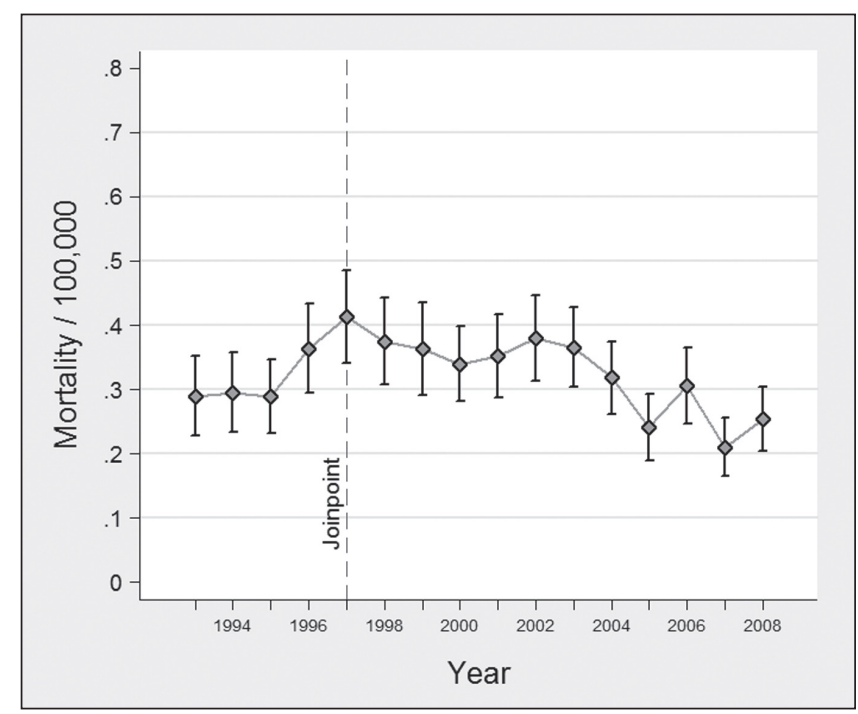

Figure 2) Annual mortality rates for ischemic colitis patients requiring colectomy in the United States between 1993 and 2008

study that validated ICD-9 coding demonstrated that the majority of cases represented ischemic colitis (22). Second, the NIS database extracts data from discharge abstracts, which prevents investigators from following patient outcomes postdischarge. Third, the NIS database does not provide data on preadmission or in-hospital medications and, thus, we could not directly study the effects of medication use that have been examined in other studies $(23,24)$. Fourth, although the sampling frame of the NIS has been shown to represent $>90 \%$ of all hospitalizations, Veteran Affairs hospitals were not included in the NIS database. Thus, the annual civilian population size for the US was used as the denominator for incidence and mortality calculations.

\section{CONCLUSION}

Our population-based study evaluated the incidence of colectomy for ischemic colitis in the US using a nationally representative sample. In the latter years of our study, the incidence of colectomy for ischemic colitis stabilized and mortality rates decreased. This was an important finding because $20 \%$ of patients died postoperatively. Additional prospective studies in this area will elucidate clinical and medication-related parameters for treatment, early detection, natural disease history, and risk factor modification to decrease adverse outcomes and overall burden of this important disease.

DISCLOSURES: The authors have no financial disclosures or conflicts of interest to declare.

ACKNOWLEDGEMENTS: Dr Gilaad Kaplan is supported by a New Investigator Award from the Canadian Institutes of Health Research and a Population Health Investigator Award from Alberta-Innovates Health Solutions.

AUTHOR CONTRIBUTIONS: Matthew D Sadler - participated in conceiving the study idea, developing the study design, interpreting results and writing of the manuscript. Nikila C Ravindran - participated in conceiving the study idea, developing the study design, interpreting results and editing the manuscript. James Hubbard - participated in developing the study design, analyzing the results and editing the manuscript. Robert P Myers participated in developing the study design, interpreting results and editing the manuscript. Subrata Ghosh - participated in developing the study design, interpreting results and editing the manuscript. Paul L Beck - participated in developing the study design, interpreting results and editing the manuscript. Elijah Dixon - participated in developing the study design, interpreting results and editing the manuscript. Chad Ball - participated in developing the study design, interpreting results and editing the manuscript. 
Chris Prusinkiewicz - participated in developing the study design, interpreting results and editing the manuscript. Steven J Heitman - participated in developing the study design, interpreting results and editing the manuscript. Gilaad G Kaplan - participated in conceiving the study idea, developing the study design, preparing the data, supervising the analysis, interpreting

\section{REFERENCES}

1. Huguier M, Barrier A, Boelle PY, Houry S, Lacaine F. Ischemic colitis. Am J Surg 2006;192:679-84.

2. Sotiriadis J, Brandt LJ, Behin DS, Southern WN. Ischemic colitis has a worse prognosis when isolated to the right side of the colon. Am J Gastroenterol 2007;102:2247-52.

3. Arnott ID, Ghosh S, Ferguson A. The spectrum of ischaemic colitis. Eur J Gastroenterol Hepatol 1999;11:295-303.

4. Higgins PD, Davis KJ, Laine L. Systematic review: The epidemiology of ischaemic colitis. Aliment Pharmacol Ther 2004:19:729-38.

5. Brandt LJ. Bloody diarrhea in an elderly patient. Gastroenterology 2005;128:157-63.

6. Whalen D EA. HCUP Nationwide Inpatient Sample (NIS) Comparison Report: U.S. Agency for Healthcare Research and Quality; 2004.

7. Gorham ED, Garland CF, Garland FC. Acid haze air pollution and breast and colon cancer mortality in 20 Canadian cities. Can J Public Health 1989;80:96-100.

8. Kaplan GG, Hubbard J, Panaccione R, et al. Risk of comorbidities on postoperative outcomes in patients with inflammatory bowel disease. Arch Surg 2011;146:959-64.

9. Kaplan GG, McCarthy EP, Ayanian JZ, Korzenik J, Hodin R, Sands BE. Impact of hospital volume on postoperative morbidity and mortality following a colectomy for ulcerative colitis. Gastroenterology 2008;134:680-7.

10. Meddings L, Myers RP, Hubbard J, et al. A population-based study of pyogenic liver abscesses in the United States: Incidence, mortality, and temporal trends. Am J Gastroenterol 2010;105:117-24.

11. Kaplan GG, Panaccione R, Hubbard JN, et al. Inflammatory bowel disease patients who leave hospital against medical advice: Predictors and temporal trends. Inflamm Bowel Dis 2009;15:845-51.

12. Deyo RA, Cherkin DC, Ciol MA. Adapting a clinical comorbidity index for use with ICD-9-CM administrative databases. J Clin Epidemiol 1992;45:613-9.

13. Lee TC, Wang HP, Chiu HM, et al. Male gender and renal dysfunction are predictors of adverse outcome in nonpostoperative ischemic colitis patients. J Clin Gastroenterol 2010;44:e96-100.

14. Brandt LJ, Feuerstadt P, Blaszka MC. Anatomic patterns, patient characteristics, and clinical outcomes in ischemic colitis: A study of results and writing the manuscript. Dr Kaplan confirms that he has had full access to all of the data in the study and had final responsibility for the decision to submit for publication. All authors reviewed and approved the final version of the manuscript.

313 cases supported by histology. Am J Gastroenterol 2010;105:2245-52.

15. Nguyen GC, Bayless TM, Powe NR, Laveist TA, Brant SR. Race and health insurance are predictors of hospitalized Crohn's disease patients undergoing bowel resection. Inflamm Bowel Dis 2007;13:1408-16.

16. Montoro MA, Brandt LJ, Santolaria S, et al. Clinical patterns and outcomes of ischaemic colitis: results of the Working Group for the Study of Ischaemic Colitis in Spain (CIE study).

Scand J Gastroenterol 2011;46:236-46.

17. Flobert C, Cellier C, Berger A, et al. Right colonic involvement is associated with severe forms of ischemic colitis and occurs frequently in patients with chronic renal failure requiring hemodialysis. Am J Gastroenterol 2000;95:195-8.

18. Paterno F, McGillicuddy EA, Schuster KM, Longo WE. Ischemic colitis: Risk factors for eventual surgery. Am J Surg 2010;200:646-50.

19. Mosele M, Cardin F, Inelmen EM, et al. Ischemic colitis in the elderly: Predictors of the disease and prognostic factors to negative outcome. Scand J Gastroenterol 2010;45:428-33.

20. Ma C, Crespin M, Proulx MC, et al. Postoperative complications following colectomy for ulcerative colitis: A validation study. BMC Gastroenterol 2012;12:39.

21. Molodecky NA, Panaccione R, Ghosh S, Barkema HW, Kaplan GG. Challenges associated with identifying the environmental determinants of the inflammatory bowel diseases. Inflamm Bowel Dis 2011;17:1792-9.

22. Sands BE, Duh MS, Cali C, et al. Algorithms to identify colonic ischemia, complications of constipation and irritable bowel syndrome in medical claims data: Development and validation. Pharmacoepidemiol Drug Saf 2006;15:47-56.

23. Walker AM, Bohn RL, Cali C, Cook SF, Ajene AN, Sands BE. Risk factors for colon ischemia. Am J Gastroenterol 2004;99:1333-7.

24. Cole JA, Cook SF, Sands BE, Ajene AN, Miller DP, Walker AM. Occurrence of colon ischemia in relation to irritable bowel syndrome. Am J Gastroenterol 2004;99:486-91. 


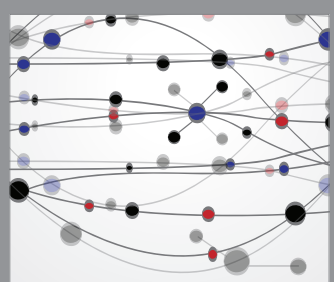

The Scientific World Journal
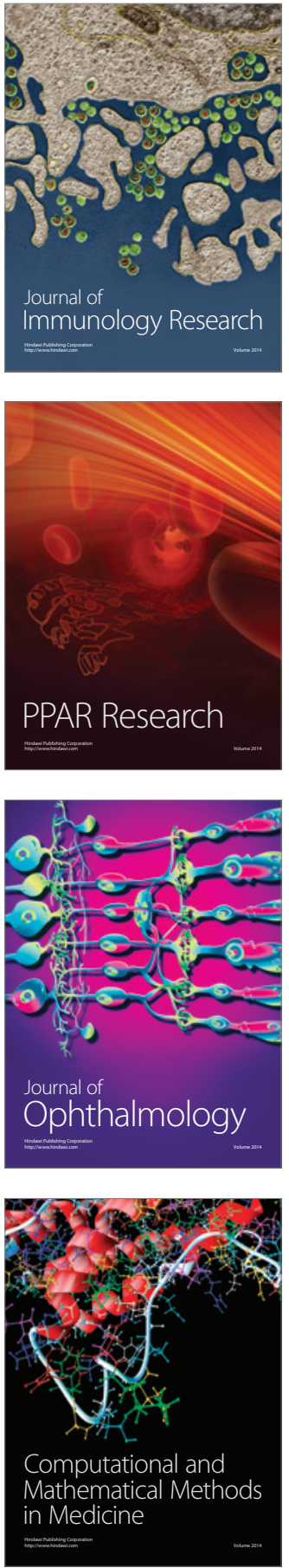

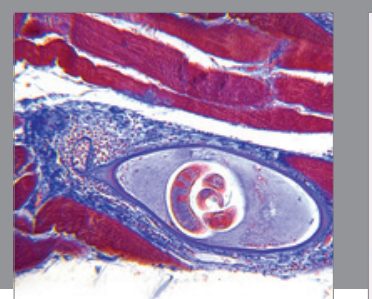

Gastroenterology Research and Practice

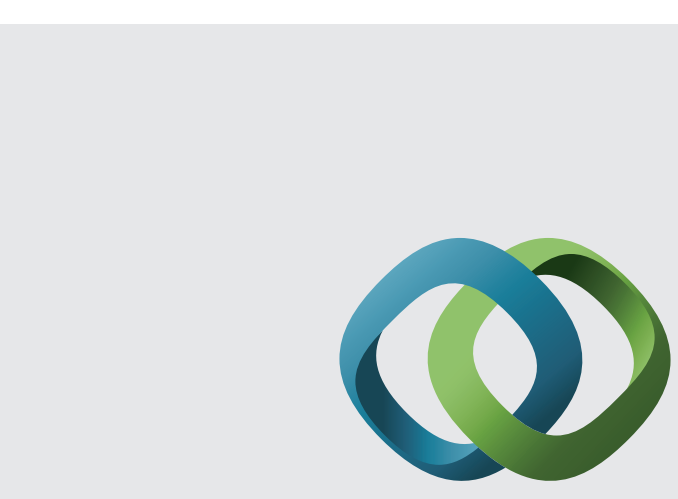

\section{Hindawi}

Submit your manuscripts at

http://www.hindawi.com
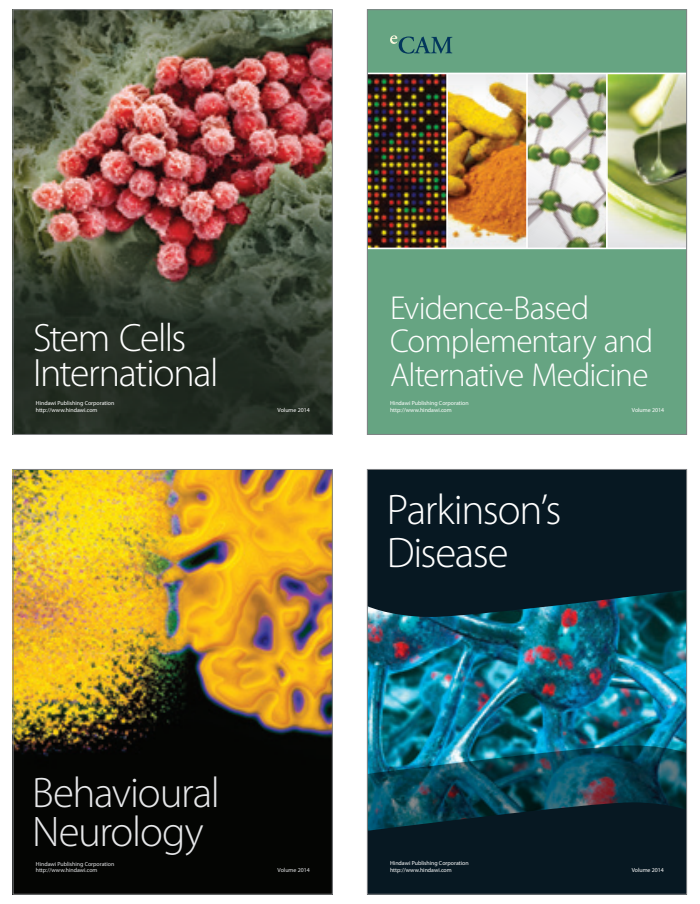
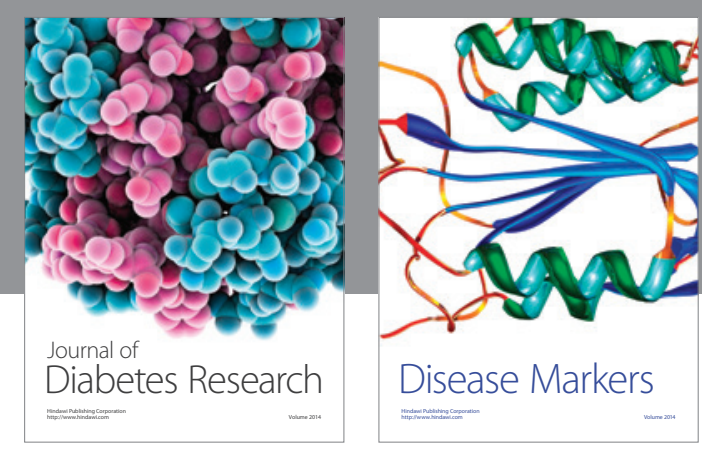

Disease Markers
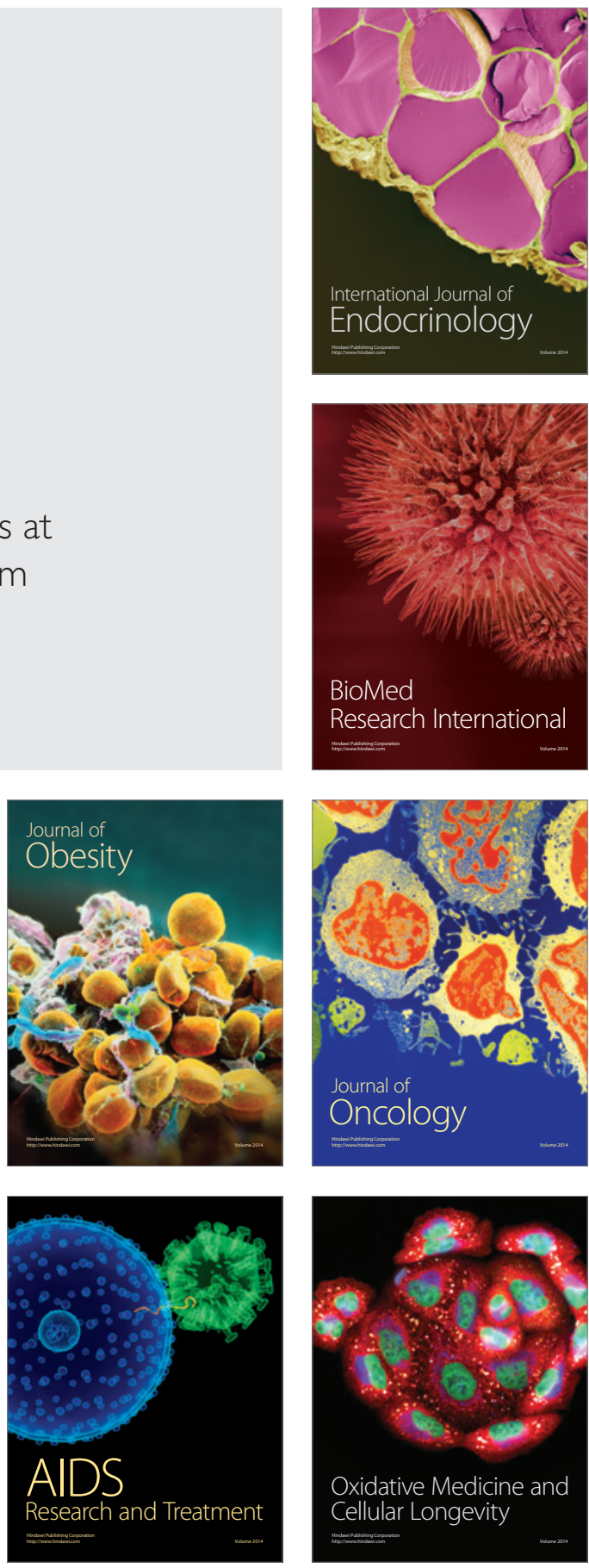